\title{
Prevalence of Cardiovascular Risk Factors on Different Phases of Diabetic Nephropathy in Comparison to Type 1 Diabetes Recipients who had Undergone Simultaneous Pancreas Kidney Transplant
} Maria Deolinda F Neves ${ }^{1}$, Erika B Rangel ${ }^{2 *}$, João R Sá1 and Sergio A Dib ${ }^{1}$

${ }^{1}$ Department of Medicine, Division of Endocrinology, São Paulo Federal University, Brazil ${ }^{2}$ Department of Medicine, Division of Nephrology, São Paulo Federal University, Brazil

\begin{abstract}
The aims of this study were to evaluate the relationship between different phases of diabetic nephropathy and the beneficial effect of successful simultaneous pancreas-kidney transplant (SPKT) on the prevalence of cardiovascular risk factors (CVRF). We analyzed 210 type 1 diabetic patients (age>18 years and diabetes duration $\geq 10$ years). Patients were divided into five groups: normo, micro, macroalbuminuric, end stage renal disease (ESRD), and SPKT. The following CVRF, besides diabetes, were analyzed: blood pressure, waist circumference, HDL cholesterol and triglycerides. The prevalence of $\geq 2$ CVRF increased from normoalbuminuric to end stage renal disease group: $20.7 \%$, $43.4 \%, 53.6 \%, 71.4 \%$ ( $<<0.001$ ), respectively. In the SPKT group, this prevalence was $18.5 \%$. Two or more CVRF were positively associated with female gender $(\mathrm{OR}=2.5 ; \mathrm{p}=0.008)$ and with diabetes duration over 15 years $(\mathrm{OR}=2.6$; $p=0.023)$. The SPKT was a protective factor $(O R=0.3 ; p=0.047)$, and $E S R D$ was a risk factor $(O R=5.2, p=0.014)$ for the presence of CVRF. In conclusion, the severity of diabetic nephropathy was associated with a higher prevalence of two or more CVRF in type 1 diabetes mellitus. After SPKT, that prevalence was similar to normoalbuminuric patients.
\end{abstract}

Keywords: Cardiovascular risk factors; Diabetic nephropathy; SPKT; Type 1 diabetes

\section{Introduction}

The relative mortality risk due to cardiovascular disease (CVD) in patients diagnosed with type 1 diabetes mellitus (type $1 \mathrm{DM}$ ) is estimated to be 10 times higher than age-matched individuals without diabetes [1]. Among the factors that contribute to this difference are those related to the development of renal disease. Notably, renal disease and younger age onset of diabetes can potentially result in longer exposure to cardiovascular risk factors (CVRF), such as hypertension, hyperlipidemia and poor glycemic control [2].

Diabetic patients with renal disease are at the greatest risk for presenting multiple CVRF, and the progression and severity of renal disease can increase all causes of mortality [3].

The correction of uremic and hyperglycemic environment, potential cardiovascular risk factors, is achieved with simultaneous pancreas-kidney transplant (SPKT). The SPKT is a treatment option for patients with type 1 diabetes and ESRD. The life expectancy of these patients is on average 15 years longer than patients who are waiting for a transplant [4]. Although cardiovascular disease is the leading cause of death after SPKT, most studies show an improvement in risk factors for atherosclerosis and a reduction in the number of cardiovascular events [5-8].

Therefore, it is important to understand from which stage of renal disease these CVRF become more prevalent. In the same way, it would be interesting to know which group of patients with diabetic nephropathy could be compared to patients who had undergone SPKT, regarding to CVRF.

Accordingly, this study evaluates the relationship between different phases of diabetic nephropathy and the prevalence of CVRF in patients with type $1 \mathrm{DM}$. Here we also show the beneficial effect of successful SPKT on decreasing CVRF.

\section{Patients and Methods}

\section{Patients}

This study involves a cross-sectional analysis in a randomized group of patients diagnosed with type $1 \mathrm{DM}$ from an out-patient clinic of diabetes care at São Paulo Federal University Hospital, São Paulo, SP, Brazil. We defined T1DM as insulin-dependence within 6 months of diagnosis. Eligible patients were 18 years or older and had T1DM more than or equal to 10 years. Patients who have undergone simultaneous pancreas-kidney transplant (SPKT) less than 6 months prior to inclusion or who have lost renal and/or pancreatic graft function were excluded from the analysis. The study protocol was approved by the Institutional Review Board of São Paulo Federal University.

\section{Clinical and laboratory parameters}

A total of 210 patients with T1DM were studied. To aid the analysis, the total sample was divided into five groups according to the following criteria: Group NA (normal renal function without microalbuminuria), Group MI [microalbuminuria and/or use of ACE (angiotensin-converting-enzyme) inhibitors or angiotensin II receptor blockers, since introduced because of detection of microalbuminuria],

${ }^{*}$ Corresponding author: Erika B Rangel, Department of Medicine, Division of Nephrology, São Paulo Federal University, Rua Botucatu, 740, Vila Clementino SP 04023-900, Sao Paulo, Brazil, Tel: +55 11 59041699, +55 11 55739652; E-mail erikabr@uol.com.br

Received January 19, 2013; Accepted March 20, 2013; Published March 24 2013

Citation: Neves MDF, Rangel EB, Sá JR, Dib SA (2013) Prevalence of Cardiovascular Risk Factors on Different Phases of Diabetic Nephropathy in Comparison to Type 1 Diabetes Recipients who had Undergone Simultaneous Pancreas Kidney Transplant. J Diabetes Metab S9: 002. doi:10.4172/2155-6156. S9-002

Copyright: (c) 2013 Neves MDF, et al. This is an open-access article distributed under the terms of the Creative Commons Attribution License, which permits unrestricted use, distribution, and reproduction in any medium, provided the original author and source are credited. 
Citation: Neves MDF, Rangel EB, Sá JR, Dib SA (2013) Prevalence of Cardiovascular Risk Factors on Different Phases of Diabetic Nephropathy in Comparison to Type 1 Diabetes Recipients who had Undergone Simultaneous Pancreas Kidney Transplant. J Diabetes Metab S9: 002. doi:10.4172/2155-6156.S9-002

Page 2 of 6

Group MA (macroalbuminuira and/or moderately or severely impaired renal function with estimated creatinine clearance between 15 and 60 $\mathrm{mL} / \mathrm{min} / 1.73 \mathrm{~m}^{2}$ ), Group ESRD (end stage renal disease, including hemodialysis or peritoneal dialysis), Group SPKT (simultaneous pancreas kidney transplant, with both grafts functioning). Enteric exocrine drainage was performed in all SPKT recipients, except for one that underwent bladder drainage. Systemic endocrine drainage was performed using the iliac venous or inferior cava vein anastomosis in all cases. The initial immunosuppressive regimen included tacrolimus $0.15 \mathrm{mg} / \mathrm{kg} /$ day, the dose was adjusted throughout the post-transplant period to maintain the serum levels of $10-15 \mathrm{ng} / \mathrm{mL}$ in the first 30 days, $8-10 \mathrm{ng} / \mathrm{mL}$ between 31 and 90 days followed by $5-10 \mathrm{ng} / \mathrm{mL}$ of the maintenance dose. Tacrolimus was prescribed in $92 \%$ of the recipients. The initial prednisone dose was $30 \mathrm{mg} /$ day, reduced by $5 \mathrm{mg}$ each month until the $8^{\text {th }}$ month when the maintenance dose of $5 \mathrm{mg} /$ day was obtained. Mycophenolate mofetil $2 \mathrm{~g} /$ day or mycophenolate sodium $1.44 \mathrm{~g} /$ day was administered in all cases. Induction with monoclonal or polyclonal antibodies was not routinely performed. However, the induction was carried out in cases of re-transplant, when the panel reactive antibody was greater than $20 \%$ or when the cold ischemia of the organ exceeded 24 hours.

At medical visits, the following anthropometric data were registered: weight $(\mathrm{kg})$, height $(\mathrm{m})$ and abdominal circumference $(\mathrm{cm})$, which was taken halfway between the patient's $10^{\text {th }}$ rib and the iliac crest. The body mass index (BMI) was calculated by the formula: weight $(\mathrm{kg}) /$ height $^{2}(\mathrm{~m})$. Systolic and diastolic blood pressures were measured with the patient sitting down, after resting for at least 5 minutes, using a standard clinical sphygmomanometer. The average result from 3 measures taken during the same ambulatory visit was recorded.

Albuminuria was considered positive if detected in at least 2 to 3 samples within an interval of 3 months. Microalbuminuria and macroalbuminuria were defined as urinary albumin excretion rates between $20-200 \mu \mathrm{g} /$ minute and over $200 \mu \mathrm{g} /$ minute, respectively. Renal function was estimated using the Cockcroft-Gault formula.

The following cardiovascular risk factors (CVRF) were analyzed: arterial systolic pressure $\geq 130 \mathrm{mmHg}$ and/or diastolic $\geq 85 \mathrm{mmHg}$ and/or use of antihypertensives, abdominal circumference $\geq 80 \mathrm{~cm}$ for females and $\geq 90 \mathrm{~cm}$ for males, HDL-cholesterol $<50 \mathrm{mg} / \mathrm{dL}$ for females and $40 \mathrm{mg} / \mathrm{dL}$ for males, triglycerides $\geq 150 \mathrm{mg} / \mathrm{dL}$, fasting glycemia $\geq$ $100 \mathrm{mg} / \mathrm{dL}$ and or use of anti-hyperglycemic specific agent. This last criterion was fulfilled in all of the patients from groups NA, MI, MA and ESRD (diabetic patients).

Laboratory parameters were analyzed according to the following methods: total cholesterol (colorimetric enzymatic method: reference $<200 \mathrm{mg} / \mathrm{dL}$ ), HDL-cholesterol (colorimetric method: reference $>35 \mathrm{mg} / \mathrm{dL}$ ), LDL-cholesterol (Friedewald formula), triglycerides (colorimetric enzymatic method: reference $<150 \mathrm{mg} / \mathrm{dL}$ ), glycemia (Hitachi 912 Roche enzymatic method: reference of $75-99 \mathrm{mg} / \mathrm{L}$ ), glycated hemoglobin (high-performance liquid chromatography, reference range: 3.5-6.0\%; Tosoh Bioscience, scenika@scenica.com. br), and albuminuria (imunoturbidimetric method: reference up to 20 $\mu \mathrm{g} / \mathrm{min})$.

\section{Statistical analysis}

Because most quantitative variables had no adherence to the normal distribution ( $\mathrm{p}<0.05$ in the Kolmogorov-Smirnov test), a nonparametric test was chosen to evaluate them. The comparison between groups NA to ESRD, regarding quantitative variables, was performed by the Kruskall-Wallis test. In order to compare these groups to each other, the Tukey test of multiple comparisons was performed. To compare the quantitative variables among the SPKT variables and the other groups, the Mann-Whitney test was used. For the qualitative variables, the linear tendency and association were calculated by the chi-square test.

Additionally, to evaluate these factors in the total sample of patients, association was analyzed by the chi-square test (univariate analysis), selecting the factors with $\mathrm{p}<0.20$. For this analysis, the patients' ages and age at diagnosis were split into tertiles: 18-23, 24-34, and 35-62 years old, and 1-6, 7-12, 13-35 years, respectively. Time on dialysis was also analyzed. After selecting factors by a univariate analysis, a multiple logistic regression analysis was performed. The Hosmer-Lemeshow test was used to verify model adjustment. In the statistical analyses, SPSS 11.0 software was used.

\section{Results}

\section{General patient characteristics}

Patients were classified in five groups ( $\mathrm{n}=210)$ : NA: $29(13.8 \%), \mathrm{MI}$ 53 (25.2\%), MA: 28 (13.3\%), ESRD: 35 (16.7\%), and SPKT: 65 (31\%). Table 1 compares the demographic and clinical characteristics of the five groups.

\begin{tabular}{|c|c|c|c|c|c|c|}
\hline Dro & NA & MI & MA & ESRD & SPKT & Multiple comparisons \\
\hline $\mathrm{N}$ & 29 & 53 & 28 & 35 & 65 & ------ \\
\hline Gender M (\%) & 48.3 & 50.9 & 60.7 & 45.7 & 41.5 & ------ \\
\hline Age (years) & $21.9(4.7) \#$ * & $26.4(10.5)^{\star}$ & $31.5(8.1)^{\star}$ & $32.6(8.7)^{\star}$ & $36.0(7.3)$ & $\begin{array}{l}\text { NA lower than MA and ESRD } \\
\text { MI lower than ESRD } \\
\text { All groups were lower than SPKT }\end{array}$ \\
\hline Type 1 DM duration (years) & $15.0(4.6)^{*}$ & $17.2(7.4)^{*}$ & $20.4(5.6)$ & $18.8(4.5)$ & $20.6(5.2)$ & $\begin{array}{c}\text { NA lower than MA, ESRD and SPKT } \\
\text { MI lower than SPKT }\end{array}$ \\
\hline $\begin{array}{l}\text { Age at the diagnosis } \\
\text { (years) }\end{array}$ & $6.9(3.5)^{\star}$ & $9.1(6.6)^{*}$ & $11.0(7.9)$ & $13.5(7.5)$ & $13.0(6.9)$ & $\begin{array}{c}\text { NA and MI lower than MA,ESRD } \\
\text { and SPKT }\end{array}$ \\
\hline
\end{tabular}

NA: Normoalbuminuria; MI: Microalbuminuria; MA: Macroalbuminuria; ESRD: End Stage Renal Disease; SPKT: Simultaneous Pancreas Kidney Transplant \# Data are shown as mean (S.D.) * $p<0.05$

Table 1: Demographic and clinical data. 
Citation: Neves MDF, Rangel EB, Sá JR, Dib SA (2013) Prevalence of Cardiovascular Risk Factors on Different Phases of Diabetic Nephropathy in Comparison to Type 1 Diabetes Recipients who had Undergone Simultaneous Pancreas Kidney Transplant. J Diabetes Metab S9: 002. doi:10.4172/2155-6156.S9-002

Page 3 of 6

The patients' cardiovascular risk factors were distributed as follows: high blood pressure $70 \%$, high abdominal circumference $33.8 \%$, low HDL-cholesterol $28.1 \%$ and high triglycerides $15.2 \%$. Overall, two or more risk factors were diagnosed in $38.6 \%$ of all patients.

In ESRD patients, average time on dialysis (23.1 months) was similar to that reported for SPKT recipients (27.9 months). The majority $(81 \%)$ of those patients were on hemodialysis.

In the SPKT group, the time elapsed after transplant averaged 28.6 months (range 6-75 months) by the time of the study.

\section{Demographic data and cardiovascular risk factors prevalence on type $1 \mathrm{DM}$ in different phases of renal disease}

ESRD patients showed lower BMI compared to all other groups $(\mathrm{p}<0.05)$ and lower abdominal circumference than the MI group $(\mathrm{p}<0.05)$. Glycemic control $(\mathrm{HbA1c})$ was similar in all four diabetic groups studied. The ESRD group also exhibited the highest levels of systolic blood pressure (SBP) $(\mathrm{p}<0.05)$ and higher diastolic blood pressure (DBP) compared to the NA and MI groups $(\mathrm{p}<0.05)$.

Table 2 illustrates that in the MA, serum total cholesterol was higher $(\mathrm{p}<0.05)$ than in the NA groups, whereas serum LDL-cholesterol was higher than the ESRD group $(\mathrm{p}<0.05)$. Additionally, in the ESRD group, serum HDL-cholesterol was lower than the MI group $(\mathrm{p}<0.05)$ and serum triglycerides were higher when compared to the other groups $(\mathrm{p}<0.05)$. Antihypertensive drugs were reported in all groups: $3.4 \%(\mathrm{NA}), 54.7 \%(\mathrm{MI}), 100 \%(\mathrm{MA})$, and $94.3 \%$ (ESDR). In addition, lipid lowering drugs were prescribed: $6.9 \%(\mathrm{NA}), 15.1 \%(\mathrm{MI}), 67.9 \%$ (MA), and $25.7 \%$ (ESRD).

The prevalence of two or more cardiovascular risk factors was described in $20.7 \%$ (NA), $43.4 \%$ (MI), 53.6\% (MA), and 71.4\% (ESRD). In light of these findings, we observed that after applying the chi-square for a trend test, there was a tendency toward increasing multiple risk factors prevalence according to the advance of diabetic nephropathy $(\mathrm{p}<0.001)$.

\begin{tabular}{|c|c|c|c|c|c|c|c|}
\hline Dro & $\begin{array}{c}1 \\
N A \\
(N=29) \\
M(S D)\end{array}$ & $\begin{array}{c}2 \\
M I \\
(N=53) \\
M(S D)\end{array}$ & $\begin{array}{c}3 \\
\text { MA } \\
(N=28) \\
M(S D)\end{array}$ & $\begin{array}{c}4 \\
\text { ESRD } \\
(\mathrm{N}=35) \\
M(S D)\end{array}$ & $\begin{array}{c}\text { Multiple } \\
\text { Comparisons } \\
\text { (groups } 1 \text { to } 4 \text { ) }\end{array}$ & $\begin{array}{c}5 \\
\text { SPKT } \\
(N=65) \\
M(S D)\end{array}$ & $\begin{array}{c}\text { Group } 5 \\
\text { vs } \\
1,2,3,4\end{array}$ \\
\hline BMI $\left(\mathrm{Kg} / \mathrm{m}^{2}\right)$ & $22.9(2.7)$ & $24.1(3.4)$ & $23.4(3.4)$ & $20.9(2.4)$ & $4<1,2$ e 3 & $22.7(3.4)$ & $\begin{array}{l}5<2(p=0.023) \\
5>4(p=0.008)\end{array}$ \\
\hline Abdominal circumference $(\mathrm{cm})$ & $78.7(9.8)$ & $83.6(9.2)$ & $80.5(8.8)$ & $78.6(7.5)$ & $2>4$ & $84.3(10.4)$ & $\begin{array}{l}5>1(p=0.008) \\
5>4(p=0.003)\end{array}$ \\
\hline $\mathrm{SBP}(\mathrm{mmHg})$ & $116(8.1)$ & $123(15.3)$ & $132.3(22.9)$ & $150.5(31.2)$ & $\begin{array}{c}1<3 \\
4>1,2 \text { e } 3\end{array}$ & $128.7(16.6)$ & $\begin{array}{l}5>1 \quad(p=0.000) \\
5>2(p=0.017) \\
5<4 \quad(p<0.001)\end{array}$ \\
\hline $\mathrm{DBP}(\mathrm{mmHg})$ & $76.2(8.5)$ & $79.3(10.3)$ & $86.6(13.5)$ & $91.1(16.2)$ & $\begin{array}{c}1<3 \\
4>1 \text { e } 2\end{array}$ & $81.3(11.5)$ & $\begin{array}{l}5>1(p=0.033) \\
5<4(p=0.001)\end{array}$ \\
\hline Total cholesterol (mg/dL) & $160.6(25.8)$ & $166.1(30.4)$ & $186.8(46.4)$ & $166(45.4)$ & $1<3$ & $146(24)$ & $\begin{array}{l}5<1 \quad(p=0.009) \\
5<2(p<0.001) \\
5<3 \quad(p<0.001) \\
5<4 \quad(p=0.032)\end{array}$ \\
\hline LDL cholesterol (mg/dL) & $92.4(21.5)$ & $92.3(24.1)$ & $108.7(38.6)$ & $85.4(43.8)$ & $3>4$ & $68.8(20)$ & $\begin{array}{l}5<1 \quad(p<0.001) \\
5<2(p<0.001) \\
5<3(p<0.001)\end{array}$ \\
\hline HDL-cholesterol (mg/dL) & $49.6(12.3)$ & $55.5(13.3)$ & $53.6(15.2)$ & $47.6(15.2)$ & $2>4$ & $58.6(16.3)$ & $\begin{array}{l}5>1(p=0.005) \\
5>4(p=0.002)\end{array}$ \\
\hline Triglycerides (mg/dL) & $89.9(31.6)$ & $96.3(65.5)$ & $101.7(48.1)$ & $160.1(89.3)$ & $4>1,2$ e 3 & $92.8(36.4)$ & $5<4(p<0.001)$ \\
\hline $\mathrm{A} 1 \mathrm{C}(\%)$ & $9.1(2)^{\mathrm{a}}$ & $8.7(2)^{\mathrm{b}}$ & $8.9(1.6)^{c}$ & $8.8(2.3)^{\mathrm{d}}$ & ---- & $5.3(0.6)^{\mathrm{e}}$ & $\begin{array}{l}5<1 \quad(p<0.001) \\
5<2(p<0.001) \\
5<3(p<0.001) \\
5<4(p<0.001)\end{array}$ \\
\hline
\end{tabular}

SBP: Systolic Blood Pressure; DBP: Diastolic Blood Pressure

a: $\mathrm{N}=26, \mathrm{~b}: \mathrm{N}=49$, c: $\mathrm{N}=22$, d: $\mathrm{N}=20$, e: $\mathrm{N}=39$

$\mathrm{p}=$ comparison of each one of the groups with SPKT (Mann- Whitney Test)

Table 2: Comparison of clinical and biochemical parameters in different phases of renal disease and SPKT. 
Citation: Neves MDF, Rangel EB, Sá JR, Dib SA (2013) Prevalence of Cardiovascular Risk Factors on Different Phases of Diabetic Nephropathy in Comparison to Type 1 Diabetes Recipients who had Undergone Simultaneous Pancreas Kidney Transplant. J Diabetes Metab S9: 002. doi:10.4172/2155-6156.S9-002

Page 4 of 6

\section{Comparison between SPKT and the other groups studied}

In the SPKT group, BMI $\left(22.7 \pm 3.4 \mathrm{~kg} / \mathrm{m}^{2}\right)$ was lower than the BMI observed in the MI group $\left(24.1 \pm 3.4 \mathrm{~kg} / \mathrm{m}^{2} ; \mathrm{p}=0.023\right)$, but higher than the ESRD group $\left(20.9 \pm 2.4 \mathrm{~kg} / \mathrm{m}^{2} ; \mathrm{p}=0.008\right)$. Additionally, the abdominal circumference $(84.3 \pm 10.4 \mathrm{~cm})$ was higher in the SPKT group compared to the NA $(78.7 \pm 9.8 \mathrm{~cm} ; \mathrm{p}=0.008)$ and MA $(80.5 \pm$ $8.8 ; \mathrm{p}=0.003$ ) groups.

In the SPKT group, mean SBP $(128.7 \pm 16.6 \mathrm{mmHg})$ was higher than the NA $(116 \pm 8.1 \mathrm{mmHg} ; \mathrm{p}=0.000)$ and $\mathrm{MI}(123 \pm 15.3 \mathrm{mmHg}$; $\mathrm{p}=0.017$ ) groups, but lower when compared to the ESRD group (150 $\pm 31.2 \mathrm{mmHg} ; \mathrm{p}<0.001)$. Furthermore, mean DBP was higher in the SPKT group $(81.3 \pm 11.5 \mathrm{mmHg})$ in comparison to the NA group $(76.2$ $\pm 8.5 \mathrm{~mm} \mathrm{Hg} ; \mathrm{p}=0.033)$, but lower than the ESRD group $(91.1 \pm 16.2$ $\mathrm{mmHg}, \mathrm{p}=0.001$ ).

The HbAlc levels were lower in the SPKT group $(5.3 \pm 0.6 \%)$ than the other groups $(9.1 \pm 2 ; 8.7 \pm 2 ; 8.9 \pm 1.6 ; 8.8 \pm 2.3 \%$ respectively NA, MI, MA and ESRD; $\mathrm{p}<0.001)$.

Moreover, the SPKT group exhibited not only the lowest levels of total cholesterol $(146 \pm 24 \mathrm{mg} / \mathrm{dL})$ when compared to the other groups ( $\mathrm{p} \leq 0.003)$, but also the lowest levels of LDL-cholesterol $(68.8 \pm 20 \mathrm{mg} /$ $\mathrm{dL})$ in comparison to the NA $(92.4 \pm 21.5 \mathrm{mg} / \mathrm{dL} ; \mathrm{p}<0.001), \mathrm{MI}(92.3 \pm$ $24.1 \mathrm{md} / \mathrm{dL} ; \mathrm{p}<0.001)$ and MA $(108.7 \pm 38.6 \mathrm{mg} / \mathrm{dL} ; \mathrm{p}<0.001)$ groups. However, HDL-cholesterol was higher in the SPKT group (58.6 \pm 16.3 $\mathrm{mg} / \mathrm{dL})$ compared to the NA $(49.6 \pm 12.3 \mathrm{mg} / \mathrm{dL} ; \mathrm{p}=0.005)$ and ESRD $(47.6 \pm 15.2 \mathrm{mg} / \mathrm{dL} ; \mathrm{p}=0.002)$ groups. Notably, in the SPKT group triglycerides were lower $(92.8 \pm 36.4 \mathrm{mg} / \mathrm{dL})$ when only compared to the ESRD group $(160.1 \pm 89.3 \mathrm{mg} / \mathrm{dL} ; \mathrm{p}<0.001)$.

Approximately half of the SPKT group were taking lipid-lowering medication $(50.8 \%)$, more than in other groups (NA=6.9\%, $\mathrm{MI}=15.1 \%$, $\mathrm{ESRD}=25.7 \%$ ), except for the MA group, in which $67,9 \%$ of patients were taking lipid-lowering medication.

Two or more cardiovascular risk factors were observed in $18.5 \%$ of the SPKT group. This prevalence was similar to that found in NA group
(20.7\%), but lower than that observed in MI (43.4\%), MA (53.6\%), and ESRD (71.4\%) groups. The most common CVRF detected in the SPKT group were, in decreasing order of prevalence, arterial hypertension (73.8\%), increase of the abdominal circumference (44.6\%), low HDLcholesterol (20.0\%), impaired fasting blood glucose (15.4\%), and hypertriglyceridemia (9.2\%). Among all these patients, $42 \%$ were using antihypertensive medication, and $50.8 \%$ were taking lipid lowering drugs.

\section{Factors associated with the presence of multiple cardiovascular risk factors}

In the univariate regression analysis (Table 3), being part of group MI, MA, or ESRD was associated with the presence of two or more CVRF: MI (OR=2.9; CI: 1.02-8.39; $\mathrm{p}=0.044)$, MA (OR=4.4; CI: 1.37 14.19; $\mathrm{p}=0.012$ ), and ESRD (OR=9.5; CI: 3.00-30.56; $\mathrm{p}<0.001)$. After adjusting for gender, age, and diabetes duration, being part of ESRD group remained a risk factor for the presence of multiple CVRF $(\mathrm{OR}=5.2 \mathrm{CI}: 1.40-18.95 ; \mathrm{p}=0.014)$, while $\mathrm{SPKT}$ was a protective factor $(\mathrm{OR}=0.3$; CI: $0.06-0.98 ; \mathrm{p}=0.047)$.

Adjustment by BMI was not conducted because of overfitting, suggesting that the excessive variables in the multiple model could compromise the model's accuracy and result in an increase of the OR and of the confidence interval.

In addition to being part of the ESRD group, there were other independent risk factors for the presence of two or more CVRF that included female gender $(\mathrm{OR}=2.5 ; \mathrm{p}=0.008)$ and diabetes duration over 15 years. Age over 35 years exhibited marginal significance $(\mathrm{OR}=3.1$; $\mathrm{p}=0.059$ ).

Dialysis time in the ESRD and SPKT groups and the elapsed time after SPKT were not associated with the presence of multiple cardiovascular risk factors.

\section{Discussion}

In this sample of young adults with type $1 \mathrm{DM}$ the prevalence

\begin{tabular}{|c|c|c|c|}
\hline & Category & OR brute (p/ Cl) & OR adjusted (p/ Cl) \\
\hline Group & $\begin{array}{l}1 \\
2 \\
3 \\
4 \\
5\end{array}$ & $\begin{array}{c}1.0 \text { (referência) } \\
2.9(0.044 / 1.02-8.39) \\
4.4(0.012 / 1.37-14.19) \\
9.5(<0.001 / 3.00-30.56) \\
0.9(0.800 / 0.29-2.59)\end{array}$ & $\begin{array}{c}1.0 \\
3.0(0.061 / 0.95-9.22) \\
2.4(0.205 / 0.62-9.02) \\
5.2(0.014 / 1.40-18.95) \\
0.3(0.047 / 0.06-0.98)\end{array}$ \\
\hline Gender & $\begin{array}{l}\mathrm{F} \\
\mathrm{M}\end{array}$ & $\begin{array}{c}1.6(0.092 / 0.92-2.84) \\
1.0 \text { (referência) }\end{array}$ & $\begin{array}{c}2.5(0.008 / 1.27-5.02) \\
1.0\end{array}$ \\
\hline Age (years) & $\begin{array}{l}18-23 \\
24-34 \\
35-62\end{array}$ & $\begin{array}{c}1.0 \text { (referência) } \\
1.9(0.078 / 0.93-3.81) \\
1.9(0.084 / 0.92-3.72)\end{array}$ & $\begin{array}{c}1.0 \\
2.0(0.173 / 0.73-5.42) \\
3.1(0.059 / 0.95-9.75)\end{array}$ \\
\hline DM duration (Years) & $\begin{array}{l}10-15 \\
16-19 \\
20-44\end{array}$ & $\begin{array}{c}1.0 \text { (referência) } \\
2.1(0.043 / 1.02-4.26) \\
2.3(0.019 / 1.14-4.66)\end{array}$ & $\begin{array}{c}1.0 \\
2.6(0.023 / 1.14-6.09) \\
2.8(0.049 / 1.00-7.74)\end{array}$ \\
\hline BMI & $\begin{array}{c}<19 \\
19-24.9 \\
25-29.9 \\
>30\end{array}$ & $\begin{array}{c}1.6(0.385 / 0.56-4.42) \\
1.0 \text { (referência) } \\
3.5(0.001 / 1.69-7.01) \\
3.0(0.161 / 0.64-14.02)\end{array}$ & $\begin{array}{l}- \\
- \\
- \\
-\end{array}$ \\
\hline
\end{tabular}

Hosmer and Lemeshow Test of the multiple model $=0.948$

Table 3: Logistic regression analysis for the factors associated to the presence of multiple cardiovascular risk factors. 
Citation: Neves MDF, Rangel EB, Sá JR, Dib SA (2013) Prevalence of Cardiovascular Risk Factors on Different Phases of Diabetic Nephropathy in Comparison to Type 1 Diabetes Recipients who had Undergone Simultaneous Pancreas Kidney Transplant. J Diabetes Metab S9: 002. doi:10.4172/2155-6156.S9-002

of two or more CVRF increase according to the advance of diabetic nephropathy (about 2 times from microalbuminuric to ESRD group). The female gender and duration of clinical diabetes above 15 years were also positively associated. Even after adjusting for gender, age, and diabetes duration, the ESRD state presented the greatest risk for increased prevalence of CVRF, while the SPKT group appeared as a protective factor.

Here, we showed that, after excluding patients of the SPKT group, multiple CVRF were present in $47.6 \%$ of 145 type 1 DM individuals on different phases of diabetic nephropathy with average age, time of diabetes history, and BMI of 28 years, 17.8 years, and $23 \pm 3.3 \mathrm{~kg} /$ $\mathrm{m}^{2}$, respectively. This prevalence was superior to that described in the literature ( $8 \%$ to $40 \%$ ) for type 1 diabetic patient with similar time of diabetes history [9-11]. Additionally, a recent study including type 1 diabetic individuals with comparable clinical characteristics reported a lower prevalence (12\%) for two or more CVRF [10]. That difference may be explained by the fact that our type 1 diabetic population comprised a higher percentage of patients diagnosed with chronic renal failure.

Moreover, in our study we observed an increase in multiple CVRF prevalence in parallel to the worsening of diabetic nephropathy. This prevalence ranged from $20.7 \%$ in the normoalbuminuric group to $71.4 \%$ in those with ESRD. Thorn et al. analyzed 2415 patients with type $1 \mathrm{DM}$ (average age and time of diabetes history of 37 years and 22 years, respectively) that were stratified according to their urinary albumin excretion rates in normal, micro, macroalbuminuria and ESRD [11]. Those authors confirmed an increase in the CVRF prevalence associated with the progression of diabetic nephropathy in normo (28\%), micro (44\%), macroalbuminuric (62\%), and ESRD $(68 \%)$ individuals.

Patients with ESRD, similarly to the patients who had undergone SPKT, were on average older at the time of diabetes diagnosis when compared to patients in the normo and microalbuminuric groups. The age at diabetes diagnosis is reported in some studies [12,13] as a risk factor for the development of microvascular complications in T1DM. Time of DM history seems to be more critical for the development of diabetic complications, such as diabetic nephropathy, when DM is diagnosed during the pre-puberal phase in comparison to the postpuberal diagnosis. However, there is no consensus in the literature regarding the relation between age at T1DM diagnosis and the risk of developing ESRD [14].

Data from the EURODIAB IDDM Complications Study Group showed that glycemic control is positively associated with total cholesterol, triglycerides and LDL-cholesterol and is negatively associated with HDL-cholesterol level [15]. Recently, we also have shown that in a group of T1DM individuals without ESRD, for each $1 \%$ of $\mathrm{HbA} 1 \mathrm{c}$ increment, there is an increase by $22 \%$ in the probability of exhibiting two or more CVRF, even when data were adjusted for age, sex, and time from diagnosis [16]. In the present study, when we included patients with different phases of renal disease, but with similar glycemic control ( $\mathrm{HbA1c}$ ranging from $8.8 \%$ to $9.1 \%$ ), we observed that there was an increase in CVRF prevalence paralleling the progression of renal impairment. This finding suggests that other factors related to renal function might be implicated. One of these factors could be the insulin resistance, which is found mainly in stages 4 and 5 of chronic kidney disease. The mechanism of insulin resistance remains to be elucidated and appears to be post-receptor, and located in skeletal muscle. Other factors that may potentially be associated with insulin resistance are metabolic acidosis, the presence of uremic toxins, vitamin $\mathrm{D}$ deficiency, inhibition of nitric oxide production and an increase of homocysteine [17-20]. Some studies have shown a reduced sensibility to insulin in microalbuminuric compared to normoalbuminuric type $1 \mathrm{DM}$ patients with the same age, diabetes duration, and BMI [21]. Analyzing diabetic nephropathy and glomerular filtration rate (GFR), Svensson et al. [22] identified a strong correlation between GFR and insulin sensibility and showed that even small reductions in GFR (average of $58 \mathrm{~mL} / \mathrm{min} / 1.73 \mathrm{~m}^{2}$, ranging from 43 to $73 \mathrm{~mL} / \mathrm{min} / 1.73$ $\mathrm{m}^{2}$ ) can lead to insulin resistance.

In the present study, we found a tendency of the renal impairment to increase the blood pressure and triglycerides levels and decrease abdominal circumference, but not affect HDL-cholesterol. The highest values of total and LDL-cholesterol were in the group with macroalbuminuria and/or clearance $<60 \mathrm{~mL} / \mathrm{min}$. These data are in accordance with the conclusions of other studies that examined a greater number of patients and that correlated dyslipidemia to renal function [23].

In our ESRD group, the majority of patients $(>80 \%)$ were on hemodyalisis treatment. Hemodialysis treated patients exhibit a paradoxical relationship of low levels of cholesterol and higher mortality risk, since these cholesterol levels become a marker of bad nutrition [24]. In patients submitted to peritoneal dialysis, hypertriglyceridemia is even more severe and hypercholesterolemia is more prevalent, since these patients are exposed to dialyzed glucose, which raises lipogenesis [25].

We choose to evaluate patients submitted to SPKT a minimum period of 6 months after the transplant, because from this period onwards, the immunosuppressive doses, mainly from corticosteroids and calcineurin inhibitors, were lower and had less impact on metabolic parameters and kidney function. That approach was in line with the findings that kidney function reestablishment and normalization of blood glucose levels achieved after SPKT, as reported by other studies, resulted in a reduction of cardiovascular risk factors [26].

However, our SPKT group still exhibited higher blood pressure levels when compared to the normo and microalbuminuric groups. Hypertension pathogenesis after transplant seems to be multifactorial and dependent on various factors such as immunosuppressive doses (calcineurin inhibitors and corticoids), chronic kidney allograft dysfunction, familial genetic factors, and the graft's renal artery stenosis [27].

It is well established that the type of immunosuppressive regimen affects body weight, cholesterol and glycemic levels, and renal function. Overall, we found a significantly smaller prevalence of multiple CVRF in the transplanted diabetic patients $(18.5 \%)$ in comparison to the groups with diabetic nephropathy (43.4\% to $71.4 \%)$. Similar results were also found by Rogers et al. in a prospective study involving 241 patients, from the wait list for SPKT and recipients 1 year following SPKT [28]. The authors observed a significant decrease in the prevalence of these factors following the transplant, ranging from $59 \%$ to $19 \%$. In our study, the SPKT group showed a similar prevalence of multiple CVRF compared to the normoalbuminuric group (20.7\%). To note, these 2 groups were different in relation to age, time of diabetes history (superior in the transplanted group), and glycemic control (HbAlc was lower in the transplanted group).

According to the univariate regression analysis in our study, $\mathrm{HbA1c}$ levels did not show association with multiple CVRF prevalence. On the other hand, the variables of time of diabetes history greater than 15 years and female gender were positively associated with the prevalence 
Citation: Neves MDF, Rangel EB, Sá JR, Dib SA (2013) Prevalence of Cardiovascular Risk Factors on Different Phases of Diabetic Nephropathy in Comparison to Type 1 Diabetes Recipients who had Undergone Simultaneous Pancreas Kidney Transplant. J Diabetes Metab S9: 002. doi:10.4172/2155-6156.S9-002

of those risk factors. When we adjusted the analysis by gender, age, and time of diabetes history, the SPKT group was a protective factor.

This study had three major limitations. 1) It was a cross-sectional study, not a prospective study. 2) Patients' familial hypertension and type 2 diabetes backgrounds were not available for analyses. In the DCCT (Diabetes Control and Complications Trial), the patients with positive familial history for type 2 diabetes showed greater weight gain and insulin-resistance characteristics in the lipid profile $[29,30]$. Furthermore, a recent study [31] from our group showed that a familial history of diabetes was related to higher values of insulin secretion and lower insulin sensitivity in patients submitted to SPKT. 3) The study lacked a group of patients with type $1 \mathrm{DM}$ who have undergone isolated kidney transplant. This group could better elucidate the importance of normoglycemia and isolated renal function reestablishment and their relevance on the prevalence of other cardiovascular risk factors.

In conclusion, in a group of individuals with T1DM, the female gender, age, time of diabetes history, and the severity of renal disease, are important determinants for the presence of cardiovascular risk factors. Furthermore, pancreas and kidney function reestablishment following SPKT reduce the prevalence of cardiovascular risk factors to the same prevalence found in patients with T1DM and normoalbuminuria.

\section{Acknowledgments}

This study was supported by grants from Conselho Nacional de Pesquisa (CNPq) and Coordenação de Aperfeiçoamento de Pessoal de Nível Superio (CAPES) of Brazilian Federal Government.

\section{References}

1. Krolewski AS, Kosinski EJ, Warram JH, Leland OS, Busick EJ, et al. (1987) Magnitude and determinants of coronary artery disease in juvenile-onset insulin-dependent diabetes mellitus. Am J Cardiol 59: 750-755.

2. Orchard TJ, Olson JC, Erbey JR, Williams K, Forrest KY, et al. (2003) Insulin resistance-related factors, but not glycemia, predict coronary artery disease in type 1 diabetes: 10-year follow-up data from the Pittsburgh Epidemiology of Diabetes Complications Study. Diabetes Care 26: 1374-1379.

3. Groop PH, Thomas MC, Moran JL, Wadèn J, Thorn LM, et al. (2009) The presence and severity of chronic kidney disease predicts all-cause mortality in type 1 diabetes. Diabetes 58: 1651-1658.

4. Ojo AO, Meier-Kriesche HU, Hanson JA, Leichtman A, Magee JC, et al. (2001) The impact of simultaneous pancreas-kidney transplantation on long-term patient survival. Transplantation 71: 82-90

5. Biesenbach G, Konigsrainer A, Gross C, Margreiter R (2005) Progression of macrovascular diseases is reduced in type 1 diabetic patients after more than 5 years successful combined pancreas-kidney transplantation in comparison to kidney transplantation alone. Transpl Int 18: 1054-1060.

6. Jukema JW, Smets YF, van der Pijl JW, Zwinderman AH, Vliegen HW, et al. (2002) Impact of simultaneous pancreas and kidney transplantation on progression of coronary atherosclerosis in patients with end-stage renal failure due to type 1 diabetes. Diabetes Care 25: 906-911.

7. Fiorina P, La Rocca E, Astorri E, Lucignani G, Rossetti C, et al. (2000) Reversal of left ventricular diastolic dysfunction after kidney-pancreas transplantation in type 1 diabetic uremic patients. Diabetes Care 23: 1804-1810.

8. Larsen JL, Colling CW, Ratanasuwan T, Burkman TW, Lynch TG, et al. (2004) Pancreas transplantation improves vascular disease in patients with type 1 diabetes. Diabetes Care 27: 1706-1711.

9. McGill M, Molyneaux L, Twigg SM, Yue DK (2008) The metabolic syndrome in type 1 diabetes: does it exist and does it matter? J Diabetes Complications 22: $18-23$.

10. Pambianco G, Costacou T, Orchard TJ (2007) The Prediction of Major Outcomes of Type 1 Diabetes: a 12-Year Prospective Evaluation of Three Separate Definitions of the Metabolic Syndrome and Their Components and Estimated Glucose Disposal Rate: The Pittsburgh Epidemiology of Diabetes Complications Study experience. Diabetes Care 30: 1248-1254.
11. Thorn LM, Forsblom C, Fagerudd J, Thomas MC, Pettersson-Fernholm K, et al. (2005) Metabolic syndrome in type 1 diabetes: association with diabetic nephropathy and glycemic control (the FinnDiane study). Diabetes Care 28 : 2019-2024.

12. Finne $P$, Reunanen A, Stenman S, Groop PH, Grönhagen-Riska C (2005) Incidence of end-stage renal disease in patients with type 1 diabetes. JAMA 294: $1782-1787$

13. Raile K, Galler A, Hofer S, Herbst A, Dunstheimer D, et al. (2007) Diabetic nephropathy in 27,805 children, adolescents, and adults with type 1 diabetes: effect of diabetes duration, A1C, hypertension, dyslipidemia, diabetes onset and sex. Diabetes Care 30: 2523-2528.

14. Svensson M, Nystrom L, Schon S, Dahlquist G (2006) Age at onset of childhood-onset Type 1 Diabetes and the development of end-stage renal disease: A nationwide population-based study. Diabetes Care 29: 538-542.

15. Idzio-Walus B, Mattock MB, Solnica B, Stevens L, Fuller JH, et al. (2001) Factors associated with plasma lipids and lipoproteins in Type 1 diabetes mellitus: the EURODIAB IDDM Complications Study. Diabet Med 18: 786-796.

16. Giuffrida FM, Sallum CF, Gabbay MA, Gomes MB, Pires AC, et al. (2010) Relationship between glycated hemoglobin and metabolic syndrome of type 1 and type 2 diabetes: a factor analysis study. Diabetes Care 33: e80.

17. DeFronzo RA, Alvestrand A, Smith D, Hendler R, Hendler E, et al. (1981) Insulin resistance in uremia. J Clin Invest 67: 563-568.

18. Kielstein JT, Zoccali C (2005) Asymmetric dimethylarginine: a cardiovascular risk factor and a uremic toxin coming of age? Am J Kidney Dis 46: 186-202.

19. Kalantar-Zadeh K, Mehrotra R, Fouque D, Kopple JD (2004) Metabolic acidosis and malnutrition-inflammation complex syndrome in chronic renal failure. Semin Dial 17: 455-465.

20. de Boer IH (2008) Vitamin D and glucose metabolism in chronic kidney disease Curr Opin Nephrol Hypertens 17: 566-572.

21. Yip J, Mattock MB, Morocutti A, Sethi M, Trevisan R, et al. (1993) Insulin resistance in insulin-dependent diabetic patients with microalbuminuria. Lancet 342: 883-887.

22. Svensson M, Yu ZW, Eriksson JW (2002) A small reduction in glomerular filtration is accompanied by insulin resistance in type I diabetes patients with diabetic nephrophathy. Eur J Clin Invest 32: 100-109.

23. Tolonen N, Forsblom C, Thorn L, Wadén J, Rosengård-Bärlund M, et al. (2008) Relationship between lipid profiles and kidney function in patients with type 1 diabetes. Diabetologia 51: 12-20.

24. Liu Y, Coresh J, Eustace JA, Longenecker JC, Jaar B, et al. (2004) Association between cholesterol level and mortality in dialysis patients: role of inflammation and malnutrition. JAMA 291: 451-459.

25. Liu J, Rosner MH (2006) Lipid abnormalities associated with end-stage renal disease. Semin Dial 19: 32-40.

26. Tamajón LP, Miranda DM, Figueroa AC, Marrero DH, Cerdeña IL, et al. (2005) Improved cardiovascular risk profile of patients with type 1 diabetes mellitus and renal failure after simultaneous pancreas-kidney transplantation. Transplant Proc 37: 3979-3980.

27. Elliott MD, Kapoor A, Parker MA, Kaufman DB, Bonow RO, et al. (2001) Improvement in hypertension in patients with diabetes mellitus after kidney/ pancreas transplantation. Circulation 104: 563-569.

28. Rogers J, Stratta RJ, Lo A, Alloway RR (2005) Impact of the metabolic syndrome on long-term outcomes in simultaneous kidney-pancreas transplantation. Transplant Proc 37: 3549-3551.

29. Purnell JQ, Dev RK, Steffes MW, Cleary PA, Palmer JP, et al. (2003) Relationship of family history of type 2 diabetes, hypoglycemia, and autoantibodies to weigh gain and lipids with intensive and conventional therapy in the Diabetes Contro and Complications Trial. Diabetes 52: 2623-2629.

30. Thorn LM, Forsblom C, Wadén J, Söderlund J, Rosengård-Bärlund M, et al (2009) Effect of parental type 2 diabetes on offspring with type 1 diabetes Diabetes Care 32: 63-68.

31. Rangel EB, Melaragno CS, Neves MD, Dib SA, Gonzalez AM, et al. (2010) Family history of diabetes as a new determinant of insulin sensitivity and secretion in patients who have undergone a simultaneous pancreas-kidney transplant. Exp Clin Transplant 8: 29-37. 